\title{
El poder transformador del discurso y de los ejemplos personales en Agustín: Ambrosio como modelo oratorio
}

\author{
Andrés Covarrubias \\ INSTITUTO DE FILOSOFÍA \\ FACULTAD DE FILOSOFÍA \\ PONTIFICIA UNIVERSIDAD CATÓLICA DE CHILE \\ acovarrc@uc.cl
}

Resumen: San Agustín asume la retórica tradicional en términos de que el orador debe enseñar, deleitar y mover, pero la modifica al proponer que lo único necesario es lo primero. Esto en el contexto de que aunque las cosas dichas enseñen, deleiten y muevan menos, se ha de decir lo verdadero y justo, aunque no se logre el asentimiento del auditor. Una segunda diferencia es que para la retórica tradicional, las cosas pequeñas han de decirse con sencillez, las medianas con moderación y las grandes con grandilocuencia. En cambio, para el Obispo de Hipona, todo lo que predica el orador eclesiástico tiene grandeza, por estar vinculado a las Sagradas Escrituras. Este cambio de modelo solo es posible a partir del ejemplo de San Ambrosio.

Palabras clave: San Agustín, San Ambrosio, retórica, ejemplo.

Abstract: Saint Augustine assumes traditional rhetoric in terms that he must teach, delight and move, but he modifies it by proposing that to teach is the only necessary thing. This because although such things teach, delight and move less, here is need to say what is true and just, despite that the consent of the auditor cannot be assured. A second difference is that traditional rhetoric maintains that little things have to be said in a simple way, medium things have to be said with moderation, and the large things must be said grandly; however, the Bishop of Hippo says that everything that is preached by the ecclesiastical orator is great, because it is linked to the Holy Scriptures. This paradigm shift is only possible from the example of St. Ambrose.

Keywords: Saint Augustine, St. Ambrose, rhetoric, example. 


\section{INTRODUCCIÓN}

Este artículo aborda la influencia que San Ambrosio tiene sobre San Agustín desde el punto de vista de la oratoria y los elementos retóricos, considerados desde el ethos. El Obispo de Hipona paulatinamente va constatando el valor de San Ambrosio como hombre paternal y sabio, pero también como predicador bien formado en retórica, y esto al mismo tiempo le permite ir transformando de un modo decisivo ciertos aspectos cruciales de la enseñanza oratoria recibida en su juventud, principalmente a partir de la obra de Cicerón.

Una línea sugerente de investigación, y que es la que seguimos aquí, consiste en analizar la concepción que acerca de la retórica tiene San Agustín, principalmente en el De doctrina christiana, pero además haciendo hincapié tanto en ciertas observaciones provenientes de sus Confessiones como en algunos elementos gravitantes que es posible identificar en el De magistro. Junto a esto, se analizan momentos decisivos en los que el Obispo de Hipona atiende al valor del ejemplo personal en el contexto de la predicación, aspecto muy distante al lugar asignado al carácter (ethos) e historia vital del orador, tanto en la tradición griega como en la romana.

En una época como la de San Agustín y San Ambrosio, tan fuertemente marcada por la tendencia del arte retórico a la grandilocuencia y al género judicial, que a veces busca vencer a toda costa, comienza a tomar un lugar central el discurso orientado hacia la verdad entregada por las Sagradas Escrituras, donde ya humildad y grandeza, simplicidad y profundidad comienzan a convivir en un discurso que, más allá de la ocupación exclusiva por las palabras, busca interpretar el espíritu detrás de la letra. Este cambio de perspectiva permite, entre otros aspectos de principal importancia, que San Agustín pueda valorizar con fuerza y determinación las Sagradas Escrituras, pasando por sobre los obstáculos planteados por la doctrina maniquea, y que en un momento lo empujaron a despreciar esas lecturas en favor de otras ${ }^{1}$.

1 Para la contextualización de este importante aspecto, cf. H.-I. MArrou, Saint Augustin et la fin de la culture antique (De Broccard, Paris,1938). 
En este contexto, San Ambrosio comienza a representar verdaderamente para San Agustín ya no solo el orator perfectus buscado por Cicerón, sin poder jamás encontrarlo, o el vir bonus dicendi peritus, que encarna el ideal supremo del arte en Quintiliano ${ }^{2}$, aunque a veces deba mentir para lograr persuadir al auditorio, sino un ejemplo basado en la dimensión personal que irradia, mediante gestos, obras y palabras, una forma enteramente nueva de concebir la sabiduría, tal como lo hicieron San Cipriano y San Ambrosio, los que buscando siempre la salud del alma de quienes les escuchaban mediante la exposición de la verdad, se destacaron a la vez por un uso magistral de los tres géneros de dicción, a saber; humilde, medio y grande.

\section{RetóRICA y SABIDURÍA EN DE DOCTRINA CHRISTIANA ${ }^{3}$}

San Agustín 4 afirma que en el discurso se debe querer agradar más con la doctrina que con las palabras, puesto que uno habla mejor cuando dice la verdad (De doctrina christiana, IV, 28, 61), de manera que hay que amar la verdad en las palabras y no estas por sí mismas (IV, 11, 26). En este contexto, el Obispo de Hipona expresa su total rechazo a la mentira como medio para producir persuasión, asumiendo, sin embargo, que la oratoria puede tanto persuadir sobre lo bueno como sobre lo malo. En efecto, quien es justo tiene un corazón tan puro y sencillo que nunca se aparta de la verdad, ni para agradar a los demás ni para evitar un mal (II, 7, 11). Solo

2 J.J. Murphy, Rhetoric in the Middle Ages: A bistory of Rhetorical Theory from St. Augustine to the Renaissance (University of California Press, Berkeley-Los Angeles-London 1981) 22 , nota 45 , sostiene que la mayor contribución de Quintiliano a la educación retórica desde el siglo I en adelante se relaciona con su programa educativo del orador ideal (vir bonus dicendi peritus), y que, en el período clásico, sus preceptos suministraron el modelo (model) para las escuelas provinciales romanas, el cual después fue considerado por los Padres de la Iglesia, por ejemplo, Ambrosio, Jerónimo, Agustín, Eusebio de Cesarea, Basilio de Cesarea y Juan Crisóstomo.

3 Para profundizar en aspectos relacionados con este primer apartado y su vinculación con la retórica de Quintiliano, cf. A. Covarrubias, "La superación de la tensión entre sabiduría, filosofía y retórica en Quintiliano y San Agustín”, en Pensamiento; Revista de Investigación e Información Filosófica 70/262 (2014) 39-56.

4 Para las referencias a Agustín de Hipona: Las confesiones, en Obras de San Agustín, vol. II, BAC, Madrid ${ }^{8}$ 1991; De la utilidad de creer, en Obras de San Agustín, vol. IV, BAC, Madrid 1948; De la doctrina cristiana, en Obras de San Agustín, vol. XV, BAC, Madrid² 1969; De magistro, en Obras de San Agustín, vol. III, BAC, Madrid 1971. 
a partir de la sabiduría verdadera es posible hacer el bien en la comunidad, aunque se llegue a menos personas por no usar la elocuencia, ya que con la sola elocuencia, sin sabiduría, se puede producir mucho daño en las ciudades o, al menos, nada provechoso (IV, 5, 7).

En efecto, además de las reglas de la lógica y la dialéctica, existen reglas de una disputa más amplia, llamada elocuencia (eloquentia). Tales reglas son verdaderas, aunque pueda persuadirse lo falso. De esto no es responsable la retórica, sino la perversidad de quienes la usan mal. Tampoco estas reglas han sido instituidas por los hombres, por ejemplo, que arrastren al oyente, o que una narración clara y breve sea más efectiva, o que la variedad impida el tedio del auditorio (II, 36, 54).

San Agustín dice que una vez aprendida la elocuencia, esta debe ser usada más para exponer lo que hemos entendido que para comprender lo que ignoramos. Pero ni la lógica, ni la dialéctica ni la elocuencia pueden hacernos pensar que, por el solo hecho de poseerlas, hemos alcanzado la verdad que conduce a la vida eterna (II, 37, 55). Esto último no contradice el hecho de que los autores sagrados usaran todos los tropos de los gramáticos, e incluso aportaran otros nuevos, pues estos se encuentran de modo abundante en el habla común (III, 29, 41). En todo caso, lo que importa es aquello que se busca; la verdad. Las reglas a veces permiten ejercitar la inteligencia, pero también pueden hundirnos en la soberbia y la mentira y, pensando que este conocimiento es muy valioso, quienes las usan intentan por todos los medios doblegar a los que son buenos e inocentes (II, 37, 55).

Ahora bien, San Agustín destaca a los platónicos como quienes mejor se acercaron a ciertas verdades de la fe, pero, con todo, es mucho menor la ciencia que está en los libros paganos, aunque sea útil, que la contenida en las Sagradas Escrituras (II, 42, 63), las que enseñan con humildad, sublimidad y sencillez todo lo que es necesario saber. San Agustín hace depender las verdades contenidas en la filosofía, especialmente la platónica, de la sabiduría de las Sagradas Escrituras. La elocuencia, por su parte, actúa como un medio eficaz para explicar, con la mayor claridad posible, los pasajes oscuros presentes en los Textos Sagrados, teniendo en cuenta que para el Obispo de Hipona siempre podemos encontrar pasajes más claros que permiten iluminar aquellos que no lo son, o lo son menos. 
San Agustín es rotundo al afirmar que ni en De doctrina christiana, ni en ninguna otra de sus obras, expondrá los preceptos retóricos que aprendió y enseñó en las escuelas, pues, aunque reconoce que tienen cierta utilidad, ellos deben aprenderse aparte y si se dispone de tiempo para hacerlo. De hecho, quien tenga buena inteligencia consigue la elocuencia más fácilmente leyendo y escuchando a los elocuentes, como aprenden los niños - aspecto que como veremos es central en lo que respecta a su interés inicial por San Ambrosio-, que siguiendo tales preceptos, pues los oradores siguen las reglas porque son elocuentes y no al revés, donde muchos que no las han aprendido aventajan a los que han dedicado bastante tiempo a su estudio (IV, 1, 2 y IV, 3, 4). Hay, pues, una primacía radical del que sabe razonar con sabiduría, aunque no tenga la elocuencia suficiente (IV, 5, 7). Sin embargo lo mejor, a fin de cuentas, es que la elocuencia esté al servicio de la sabiduría (IV, 6, 10).

San Agustín manifiesta su acuerdo con la oratoria tradicional romana en el sentido de que el orador debe hablar de manera que enseñe, deleite y mueva, pero la transforma, ya que lo único necesario es el enseñar (IV, $12,28)^{5}$. Esto en el contexto de que aunque las cosas dichas enseñen, deleiten y muevan menos, se han de decir las que son verdaderas y justas $(\mathrm{IV}, 14,30)$, donde tiene más poder la plegaria que la pericia oratoria y, en este sentido, no basta con que el orator sea un dicendi peritus (IV, 15, 32). Incluso el orador debe actuar siguiendo fiel este principio, aunque no consiga el asentimiento del oyente (IV, 17, 34).

5 P.E. Satterthwaite, “The Latin Church Fathers”, en S.T. Porter (ed.), Handbook of Classical Rhetoric in the Hellenistic Period 330 B.C.-A.D. 400 (Brill, Leiden-New York-Köln 1997) cap. 22, 692-693, afirma que la doctrina retórica de San Agustín parece diferir de los tratados clásicos en dos aspectos: su menor consideración de la elocuencia (en particular, las reglas retóricas) a favor de la verdad; y su estimación por la Biblia y los escritores cristianos como modelos literarios. Ambos elementos, especialmente el segundo, son fuertemente innovadores. En efecto, el cambio de énfasis impuesto por el Obispo de Hipona es significativo: para San Agustín, y para todos los Padres Latinos, cuando sea necesario elegir entre la Biblia y los ideales estilísticos de la retórica clásica, deben remitirse decididamente al texto sagrado. Por su parte, J.J. Murphy, "El fin del mundo antiguo: La segunda sofística y San Agustín", en J.J. Murphy (ed.), Sinopsis histórica de la retórica clásica (Gredos, Madrid 1989) 255, destaca que la posición de San Agustín respecto a la adopción de la retórica ciceroniana se contrapone a quienes pensaban que era necesario desechar la educación retórica pagana para "proponer una cultura totalmente nueva especialmente diseñada para la comunidad cristiana". 
Una diferencia fundamental entre San Agustín y la retórica tradicional, cuyos principales exponentes latinos son Cicerón y Quintiliano, es que, según estos dos últimos autores, las cosas pequeñas han de decirse con sencillez, las medianas con moderación y las grandes con grandilocuencia ${ }^{6}$. Esto podría servir, efectivamente, en el contexto de una oratoria aplicada a las causas forenses, pero no es útil para la oratoria eclesiástica, pues en ésta no hay cosas que podamos llamar pequeñas, dado que todo está encaminado a la salud no temporal de la persona, y hasta las cosas que parecen mínimas tienen relación con la justicia, la caridad y la piedad, principal preocupación del doctor ecclesiasticus (IV, 18, 35-36).

Por lo anterior, aunque el objeto de la retórica eclesiástica son las cosas grandes, el orador no siempre debe decirlas en tono elevado, sino que para enseñar utilizará el tono sencillo (submisse), para alabar o reprender el moderado (temperate), y para orientar lo que debe ser realizado el elevado (grandis) ${ }^{7}$. El ejemplo puesto por San Agustín es el modo como nos referimos a Dios, respecto al cual utilizamos los tres tonos dependiendo de lo que queramos comunicar (IV, 19, 38). Aconsejable es variar los estilos para mantener al auditor más atento (IV, 22, 51). Tanto el estilo elevado como el medio pretenden lo mismo, a saber, que se amen las buenas costumbres y se eviten las malas, y para esto se ha de usar el estilo medio y sus adornos con prudencia, pero jamás con la jactancia que suele acompañar el delectare tradicional $(\mathrm{IV}, 25,55)^{8}$.

Por tanto, el orador debe conducir a otros a la verdad, primero mediante el ejemplo personal, siendo su modo de vida como la exuberancia de su elocuencia (IV, 29, 61). Así, pues, para que se oiga al orador con total

6 Cicerón, De oratore II, 21 y Quintiliano, Institutio oratoria XII, 10, 58.

7 R.A. Lanham, $A$ handlist of rhetorical terms (University of California Press, Berkeley ${ }^{2}$ 1991) 174-176, muestra la diferencia entre el estilo humilde o plano (genus humile o extenuatum), medio (genus medium, modicum, mediocre o temperatum), y el estilo grande (genus grande o grave). El autor basa esta distinción en el grado de ornamentación del discurso. Claramente en este punto San Agustín ofrece una innovación al poner énfasis en la belleza que resplandece en la verdad de las cosas auténticamente grandes y en la inspiración del orador que en el adorno del discurso.

8 Respecto a la influencia de Cicerón en San Agustín y el cambio de perspectiva en torno a los estilos oratorios, cf. J. AuBIN, "Augustin et la rhétorique à la fin du IV siècle: quelques liens entre le De doctrina christiana et le De rhetorica", en Revue d'études augustiniennes et patristiques 60 (2014) 91-110, esp. p. 94. 
plenitud y provecho, más peso tiene su vida que toda la grandilocuencia que se pueda mostrar (IV, 27, 59-60). Para San Agustín, en efecto, el orador debe ser un ejemplo 9 , y un modelo así jamás puede basar su discurso en la mentira y el engaño, por tanto es necesario mirar a quienes han hecho la retórica más alta, sobre todo San Cipriano y San Ambrosio, que se destacaron en los tres géneros de dicción, sin apartarse de lo más importante para conducir a los hombres a su fin último (IV, 21, 45-50) ${ }^{10}$.

El oficio de la oratoria es dicere apte ad persuasionem (IV, 25, 55). Pero esta definición implica que es posible persuadir sobre la verdad y la mentira, y en este sentido la retórica es neutral (in medio posita, IV, 2, 3), por lo tanto debemos defendernos contra la mentira para que se engrandezca la virtud, atrayendo al oyente con brevedad, claridad y verosimilitud (IV, 2 , 3), siendo la claridad la exigencia fundamental del discurso desde el punto de vista de San Agustín. Esto, incluso a riesgo de sacrificar la elegancia del lenguaje y adoptar más bien el uso corriente y sus expresiones que, a veces, parecen incluso mal construidas, apartándose así de una exigencia absoluta de la utilización impecable de la lengua (IV, 10, 24).

El orador eclesiástico (eloquentem ecclesiasticum) cuando aconseja lo que ha de hacerse, no debe solo enseñar y deleitar para retener la atención del auditorio, sino que debe mover con el fin de vencer, pues hay quienes no les basta la verdad y la amenidad del discurso para manifestar su

9 Nos referimos aquí a una forma amplia de concebir el ejemplo, a diferencia del exemplum retórico entendido como recurso didáctico, más bien visto como género literario. Para una aproximación a los exempla en este sentido, cf. G. CÁNDANO, "Aproximaciones a una retórica del exemplum", en H. Beristáin, G. Ramírez (Comp.), Ensayos sobre la tradición retórica (UNAM, México 2009) 225-236.

10 C. Horn, Agustín de Hipona: una introducción (IES, Santiago de Chile 2012) 61, al referirse a la estética agustiniana, destaca la congruentia como expresión de orden. En este sentido, a nuestro juicio, es posible integrar también la correspondencia entre pensamiento, palabra y acción, como criterio de belleza de cara a cimentar una verdadera oratoria. 
asentimiento, y para esto no queda más solución que la grandeza de la elocuencia $(\mathrm{IV}, 13,29)^{11}$.

La elocuencia, cuando trata de enseñar, no ha de buscar que agrade lo que antes se aborrecía o que se haga lo que se rehusaba, sino que debe hacer que se descubra lo que estaba escondido ${ }^{12}$. Pero esto no puede ser realizado sin cuidar un buen estilo, ya que aunque debe ser amada la verdad en las palabras y no éstas por sí mismas, son pocos los que están en condiciones de abrazarla cuando se recurre a un estilo bajo e inculto, puesto que puede entorpecer la atención del auditor (IV, 11, 26). El enseñar es algo necesario, porque nadie puede hacer o no hacer lo que ignora, en cambio el flectere, el asentimiento del oyente, no lo es, como tampoco el delectare (IV, 12, 28).

En efecto, como hemos indicado, maestros en el uso de los estilos sencillo, moderado y sublime (i.e. submissae, temperate, grandis) fueron San Cipriano y San Ambrosio, y San Agustín muestra profusamente ejemplos de cómo ellos los utilizaron acertadamente para enseñar lo que debe ser comprendido $(\mathrm{IV}, 21,45-50)^{13}$.

11 San Agustín, a nuestro entender, flexibiliza la distinción entre los géneros oratorios, al vincular lo mejor de cada uno en una retórica cuyo fin es, en definitiva, que la persona busque el camino que conduce al fin último. Así ya no es tan sencillo separar los géneros en, por ejemplo, "demostrativo" u "homilítico", al modo como se expone en D. Pujante, Manual de retórica (Castalia Universidad, Madrid 2003) 82-93.

12 H. Lausberg, Manual de retórica literaria (Gredos, Madrid 1967) vol. 2, 393, destaca esta conducción de la opinión del oyente hacia lo contrario como una característica del genus grande. En esto San Agustín aporta un nuevo elemento a la retórica tradicional al dar al arte retórico una dimensión hermenéutica más allá de lo meramente controversial. R. Copeland, en "The Ciceronian Rhetorical Tradition and Medieval Literary Theory", en V. Cox, J. WARD (Eds.), The Rhetoric of Cicero in Its Medieval and Early Renaissance Commentary Tradition (Brill, Boston 2011) 239-244, en efecto, afirma que la retórica agustiniana se convierte en hermenéutica (240).

13 G.A. Kennedy, Classical Rhetoric \& Its Christian and Secular Tradition (The University of North Carolina Press, Chapel Hill ${ }^{2}$ 1999) 178, señala que de hecho las reglas de la elocuencia pueden ser aprendidas mediante la imitación (imitation) de los modelos elocuentes. Así, la imitación es la mayor herramienta pedagógica de los retóricos clásicos, basada en el canon de los modelos discutidos por Quintiliano en su Institutio oratoria, X, 1. San Agustín reemplazó ese canon por uno nuevo, a saber, el modelo aportado por las Sagradas Escrituras y los Padres de la Iglesia. 


\section{El ejemplo de San Ambrosio: una nueva perspectiva para la ORATORIA A LA LUZ DE CONFESSIONES}

En un principio, a San Agustín no le agradaron las Sagradas Escrituras por parecerle que tenían un estilo humilde, y que, en este sentido, no podían compararse con la dignidad y excelencia de los escritos de Cicerón. Después se percata de que precisamente ellas se muestran elevadas y sublimes a los ojos de quienes son humildes (Confesiones, III, 5).

En efecto, el Obispo de Hipona, atraído por los maniqueos, primero pone sus esperanzas en las enseñanzas de Fausto. Reconoce que alababa su elocuencia, la suavidad de sus palabras, y el hecho de que hablase con más gracia que los otros maniqueos (V, 3 y 6), pero el contenido de su doctrina no le satisfacía. Tampoco está de acuerdo San Agustín con quienes, por el contrario, sospechan de la verdad solo por estar dicha en un estilo copioso y elegante.

Así, pues, estando en Milán como profesor de retórica, decide aplicar la duda y suspensión del juicio, lo que también ejercita en un principio al oír predicar al Obispo Ambrosio (VI, 4), quien le sorprende sin embargo, entre otras cosas y desde un principio, por realizar sus lecturas de manera silenciosa y sin mover la lengua (VI, 3). San Ambrosio recibió a Agustín con una caridad que le impresiona. Aunque sus discursos no son tan festivos (hilarescentis) y dulces (mulcentis) como los de Fausto en el modo de decir, San Agustín se empeña exclusivamente primero en captar este modus dicendi, pues ya había perdido la esperanza de encontrar un camino cierto hacia la verdad. Sin embargo, San Agustín entiende que es una pretensión vana separar radicalmente el modo de decir, en especial la suavidad de los sermones (suavitate sermonis) de Ambrosio $(\mathrm{V}, 13)$, de las cosas dichas, y percibe que estas últimas van entrando gradualmente en su espíritu (gradatim quidem; V,14), teniendo esto como consecuencia que el Obispo de Hipona vaya convenciéndose de que las objeciones maniqueas a la fe católica pueden ser respondidas al superar una interpretación meramente literal de las Escrituras, volcándose, por el contrario, a su sentido espiritual, aspecto que aprendió de San Ambrosio y le permitió contrarrestar muchas de las críticas maniqueas a las Sagradas Escrituras. El reconocimiento a Ambrosio, quien le bautiza el año 387, es 
claro: "A él era conducido por Ti sin saberlo, para ser por él conducido a Ti sabiéndolo" (Ad eum autem ducebar abs te nesciens, ut per eum ad te sciens ducerer, V, 13, 23). Es sugerente el hecho de que San Ambrosio, afable y paternal, influye sobre todo en Agustín mediante la predicación, pues el mismo Obispo de Hipona pone de manifiesto que, pese a su amabilidad y gentileza para con él, no le da mucha oportunidad de reunirse en otro contexto que no sea el del espacio público del domingo junto con quienes iban a escuchar al Obispo de Milán (VI, 3 y, por ejemplo, Soliloquia II, 14, 26) ${ }^{14}$.

San Agustín insiste en ejercer una duda radical, lo que lo impulsa a dejar a los maniqueos, sin estar todavía convencido de que ninguna de las dos doctrinas, ni la maniquea ni la católica, ha resultado definitivamente vencedora en su inquieto espíritu. Entonces decide permanecer catecúmeno en la Iglesia Católica, oyendo a San Ambrosio predicar al pueblo todos los domingos, con la esperanza de disipar las dudas y descubrir alguna cosa cierta $(\mathrm{V}, 14)$. Suspendía su juicio, en efecto, sobre todas las cosas, hasta que se le presentaran con la misma claridad y certeza con que se entiende que siete y tres son diez (VI, 4), y para esto hay que ser capaz de "penetrar la corteza de la letra" (VI, 5).

San Agustín narra un momento crucial cuando cierto día en el que se había preparado para decir un panegírico de alabanza en presencia del emperador, y al transitar por una calle de Milán se encuentra con un mendigo al que se le veía alegre de haber satisfecho, al menos por el momento, sus necesidades. Agustín reconoce cierta semejanza de la situación de este mendigo con su propia vida, puesto que tan pasajera como la felicidad de ese mendigo es la suya, entendida ésta como un deseo no cumplido de alegre tranquilidad, y ni siquiera eso, puesto que no lo hacía feliz su ciencia, la que más bien usaba para agradar a los hombres y no con el fin de instruirlos, buscando solo el aplauso y la gloria, a partir de mentiras (VI, 6).

Además, San Agustín en este proceso de búsqueda visita a Simpliciano, el padre espiritual de San Ambrosio, quien le relata cómo Victorino, orador

14 H. Dudden, The life and times of St. Ambrose (Clarendon Press, Oxford 1935) vol. I, 343-344. 
romano y maestro de muchos senadores, y a quien él había tratado muy familiarmente cuando estuvo en Roma, abrazó el cristianismo, sabiendo que su salvación no estaba en la retórica que enseñaba ni en las doctrinas que hasta entonces había profesado públicamente en esa ciudad (VIII, 2).

A partir de estos ejemplos personales, Agustín abandona su oficio de profesor de retórica (IX, 2), y avisa a los prelados de Milán que busquen otro maestro, todo esto agudizado por la dificultad adicional de un intenso dolor en el pecho que le producía dificultades para respirar ${ }^{15}$. En un claro abandono de la duda que había mantenido, escribe a Ambrosio para que le aconseje lecturas adecuadas con el fin de prepararse para su bautismo (IX, 5).

En el contexto de esta búsqueda de la verdad por parte de San Agustín, la que pasa por diversos momentos decisivos como la influencia de su madre Santa Mónica, la lectura del Hortensio de Cicerón, su aproximación al maniqueísmo y su decepción de esa secta, su encuentro con Simpliciano, quien le muestra cuán cerca están los escritos neoplatónicos de la verdad revelada, entre otras vivencias, consideramos que hay un aspecto central al que no se le ha prestado la suficiente atención y es el hecho de que junto a la potente atracción que le produce desde su juventud la retórica, se encuentra con un gran orador, San Ambrosio, que ha sido muy bien formado en este arte central en la educación del siglo cuarto, y que, además, le ha dado un giro no conocido por San Agustín. En efecto, a los catorce o quince años de edad, Ambrosio deja la escuela del gramático y comienza a aprender del maestro de retórica, cuyos textos de lectura se basan en Cicerón, Quintiliano y otros insignes modelos de oratoria. Sin embargo, es una época marcada por una concepción de la retórica que sacrifica el sentido en favor de una exposición que solo busca ser agradable al oído,

15 J. Montoya, "La retórica, conducta de vida, en la Edad Media", en Ensayos sobre la tradición retórica, 209-224, realiza un sugerente análisis, aunque sin referirse a San Agustín, de cómo la bondad de vida y la adquisición de las virtudes se va convirtiendo en un requisito indispensable en la retórica medieval. El autor refiere a San Isidoro de Sevilla como quien concibió esto de una manera más amplia, no solo consistente en la práctica de las virtudes, sino también en una completa formación en las disciplinas cristianas y paganas. A nuestro juicio, esta es una de las motivaciones que antes impulsó a San Agustín a escribir el De doctrina christiana. 
y la búsqueda de decir las cosas verdaderas por un arte que hace que lo falso aparezca como verdadero ${ }^{16}$. A pesar de este giro que ha tomado la retórica, tanto San Ambrosio como San Agustín están convencidos de que, bien orientado, es un arte útil para la predicación. Como hemos indicado, San Agustín se admira de que San Ambrosio lo haya recibido con benevolencia y decide ir a escuchar sus prédicas, no en un principio para atender a sus contenidos, los cuales despreciaba, sino para analizar su estilo oratorio, al que no considera tan impresionante como el de Fausto, pero sí más erudito, y si al principio admira su novedosa elocuencia, tan simple y directa para una época dada más bien a los adornos del lenguaje, poco a poco va convenciéndose también de cuán verdaderamente habla ${ }^{17}$.

\section{El De magistro: mirar a través de las palabras, más allá de las PALABRAS}

Es significativo relacionar la posición que San Agustín adopta frente al lenguaje en su dimensión persuasiva y su postura frente al valor de las palabras desarrollada en el De Magistro. Si en un principio se había maravillado con la ampulosidad y los adornos del lenguaje provistos por los grandes oradores maniqueos, característica que acompaña a la oratoria como arte en el siglo IV, ahora entiende la vanidad de aquellas palabras que solo apuntan a referir otras palabras. Lo que se ha de buscar, pues, es un lenguaje que pueda ser un medio efectivo para remitirnos a la verdad, y éste ha de ser simple, al modo como opera la comunicación en un medio de franca transparencia. El dudar y no juzgar es un camino que de algún modo nos previene del error. Pero, ¿cómo ir más allá de esa vacilación permanente? San Agustín está convencido de que esto no se logra solamente con palabras. Es necesario volvernos hacia el Maestro Interior. Pero éste no es solo una palabra, es un ser personal que nos enseña. Este es el gran descubrimiento de Agustín: la verdad tiene un carácter personal. Con este hallazgo es evidente que también se transforma el horizonte y los alcances de la palabra persuasiva. Solo un contacto personal puede llevarnos más allá de la duda y la suspensión del juicio. En relación a esto último bien cabe preguntar hasta qué punto la personalidad de San

16 H. DudDen, The life and times... vol. I, 9-10.
17 H. DudDen, The life and times... vol. I, 328. 
Ambrosio, y no solo sus palabras, abrieron los ojos y oídos de un Agustín que se encontraba aún muy confundido en el inicio de su camino de búsqueda de una verdad sólida, permanente y trascendente.

La tesis del hiponense es aún más radical: no aprendemos nada por medio de los signos que se llaman palabras (verba). En este sentido, Agustín afirma: "no es el signo el que nos hace conocer la cosa, antes bien, el conocimiento de ella nos enseña el valor de la palabra, es decir, el significado que entraña el sonido" (X, 34). En efecto, ellas nos incitan solo a buscar los objetos, pero no los muestran para que los podamos conocer. Aquí toma un lugar central aquel que nos enseña verdaderamente, porque no enseña solo palabras, ya que éstas enseñan palabras, su sonido. En efecto, ni siquiera sabemos si una locución es palabra hasta no comprender qué significa y, para saberlo, necesitamos de otro que nos muestre a los sentidos o a la inteligencia lo que queremos realmente conocer.

En este momento de su reflexión, San Agustín invierte el orden de lo que pueda significar ser persuadido, si trasladamos el planteamiento agustiniano al caso específico de la retórica:

Por lo tanto, es por conocimiento de las cosas por donde se perfecciona el conocimiento de las palabras. Oyendo palabras, ni palabras se aprenden. Porque no aprendemos las palabras que conocemos, y no podemos confesar haber aprendido las que no conocemos, a no ser percibiendo su significado, que nos viene no por el hecho de oír las voces pronunciadas, sino por el conocimiento de las cosas que significan $(\mathrm{XI}, 36)^{18}$.

Esto podría ser suscrito por Platón en el Fedro. Pero Agustín va más allá al suministrar como criterio la afirmación "si no creéis, no entenderéis",

18 Rebus ergo cognitis verborum quoque cognitio perficitur, verbis vero auditis nec verba discuntur. Non enim ea verba, quae no vimus, discimus aut quae non novimus didicisse nos possumus confiteri, nisi eorum significatione percepta, quae non auditione vocum emissarum, sed rerum significatarum cognitione contingit. 
donde, en efecto, creemos todo lo que entendemos, pero no entendemos todo lo que creemos y, además, estima como cosa útil creer en muchas cosas que no se conocen (XI, 37).

Así, pues, las palabras aparecen como ayuda para dar crédito a la verdad que habita en nosotros, pero ellas no son esa verdad, y tampoco bastan para hacer efectiva la mediación del encuentro con ella:

Cuando se trata de lo que captamos con la mente, es decir, con el entendimiento y la razón, hablamos lo que vemos presente en la luz interior de la verdad, con que está iluminado y de que goza el llamado hombre interior; pero entonces también el que nos oye, si él mismo ve con una mirada simple y recta estas cosas, conoce lo que digo en virtud de su contemplación, no por mis palabras $(\mathrm{XII}, 40)^{19}$.

Pero si no son las palabras por sí mismas las que conducen a esta nueva mirada, ¿de dónde surge? Como sabemos, por mucho tiempo Agustín permanece escéptico, suspendiendo el juicio, dudando. Las palabras están ahí presentes, y sin embargo duda. Por los conceptos vertidos por el Obispo de Hipona sobre San Ambrosio, su disposición paternal, su humildad, podemos decir que el paso que va de la duda hacia la búsqueda de certeza pasa necesariamente por el ejemplo personal. En este sentido, es valorable la actitud de San Agustín al reconocer que buscaba un maestro que le pueda mostrar el camino hacia la verdad (De utilitate credendi, VIII, 20), y es en este contexto en el que identifica a San Ambrosio como quien puede acompañarlo en este proceso ${ }^{20}$.

Entonces, las palabras en definitiva reciben su contexto de realidad en

19 Cum vero de his agitur, quae mente conspicimus, id est intellectu atque ratione, ea quidem loquimur, quae praesentia contuemur in illa interiore luce veritatis, quae ipse, qui dicitur homo interior, inlustratur et fruitur; sed tum quoque noster auditor, si et ipse illo secreto ac simplici oculo videt, novit quod dico sua contemplatione, non verbis meis.

20 P. Brown, La vie de Saint Augustin (Éditions du Seuil, París 2001) 98-102. 
virtud del ethos de quien las profiere, pero no se trata de un ethos retórico, que siempre termina remitiendo a las palabras, sino un ethos personal que más bien apunta hacia el misterio de la interioridad y, en definitiva, del horizonte espiritual21. En esto la posición del Obispo de Hipona se aleja de la de Aristóteles que, en Retórica I, 2, 1356 a 5 ss., afirma que se persuade por el carácter cuando el discurso se dice de tal manera que hace al orador digno de crédito, ya que a las personas honradas les creemos más y más rápidamente, en general en todas las cosas, pero completamente en aquellas en las que no cabe la exactitud, pero añade el Estagirita que esto debe suceder por obra del discurso y no por tener prejuzgado cómo es el que habla. Por lo tanto, concluye Aristóteles, no es cierto que en el arte, como sostienen algunos tratadistas, la honradez del que habla no incorpore nada en razón de lo convincente, sino que es el carácter personal el que constituye el más firme medio de persuasión (kyriótaton ton písteon), pero manifestado en el discurso mismo para que se le pueda considerar como propio del arte retórico. En San Agustín, en cambio, no se produce esta división tan radical entre carácter y discurso, toda vez que él intentó separar ambos aspectos al escuchar a San Ambrosio y descubrió que poco a poco iba siendo conducido de uno al otro ${ }^{22}$.

Es así como es posible dar un mayor contexto de comprensión al fenómeno persuasivo en San Agustín, si consideramos en conjunto las aportaciones del De doctrina christiana, las Confessiones y el De Magistro, pues desde este horizonte podemos entender con mayor profundidad el íntimo

21 E. GiLSON, Introduction a L'Étude de Saint Augustin (Librairie Philosophique J. Vrin, París 1949) 303-306, destaca esta conducción desde la letra hacia un sentido espiritual y alegórico para interpretar las Sagradas Escrituras, propiciada por San Ambrosio, contra la posición materialista y antropomorfista impulsada por el maniqueísmo.

22 Q. Racionero, en su traducción de la Retórica de Aristóteles (Gredos, Madrid 1990) nota 34, 176-177, hace referencia a la auctoritas latina en la retórica y cómo el análisis del carácter (éthos) ha influido en tal noción. Destaca la posición divergente, en relación al punto de vista del Estagirita, de Cicerón en De oratore II, 43, y Quintiliano, Institutio oratoria IV, 2, en el sentido de valorar el influjo que ejerce la autoridad del orador sobre el auditorio antes de pronunciar el discurso. Esto, sin duda, está en la línea de Platón (Gorgias 513 c) más que en la de Aristóteles enfrentado a la retórica de la escuela gorgiana. Con todo, consideramos que San Agustín centra su atención de una manera mucho más radical en la disposición caritativa del Obispo Ambrosio, la suavidad de su discurso a partir de ella, y su compromiso con la humildad que tan bien acompaña a la verdad y a la valoración profunda de nuestra dimensión personal, más allá de lo que pueda simplemente parecer bueno al auditorio. 
lazo existente entre la disposición personal y las palabras que orientan y estimulan hacia un cambio de perspectiva vital que da un nuevo sentido a la existencia. Tal vez podríamos decir que aquello que estimuló a San Agustín en el Hortensio de Cicerón ${ }^{23}$, desde el punto de vista de buscar la sabiduría, y que se aviva con su encuentro con el neoplatonismo, se encarna de un modo personal y admirable en el ejemplo de vida ofrecido por San Ambrosio ${ }^{24}$.

\section{Conclusiones}

Uno de los aspectos destacables de la reflexión que San Agustín realiza en torno a la retórica es la validación del ejemplo personal, más allá del aprendizaje de las reglas retóricas, como el medio determinante cuando se quiere persuadir. En efecto, el momento decisivo del proceso persuasivo se da cuando se compara el discurso con la vida y las costumbres de quien lo profiere, pues es ahí donde cualquier disonancia amenaza con distanciar al auditor de lo que el orador desea comunicar. Los tres oficios del orador (officia oratoris), enseñar, deleitar y mover, adquieren así una dimensión tanto discursiva como personal. Se ve que para San Agustín este último aspecto no es asimilable en un aprendizaje meramente técnico, sino que depende de la genuina bondad del carácter, de la adquisición de la virtud, y la alegría que produce la esperanza en una vivencia verdaderamente trascendente de la vida humana.

Por el contrario, cuando el ser humano no tiene una aspiración permanente hacia un encuentro con lo verdadero, se extravía del sentido del docere, quedando el delectare como el elemento sustancial del arte persuasivo, tal como lo experimentó al oír hablar, por ejemplo, al maniqueo Fausto, en una época en la que la retórica se caracterizó muy decisivamente por la grandilocuencia. Desde esta perspectiva, cobra su pleno sentido la duda sistemática que San Agustín aplica a cualquier doctrina, conocimiento o sentimiento, hasta no estar cierto de que en eso que es pensado o sentido

23 Para un estudio sobre la influencia de esta obra en San Agustín, cf. M.C. DolBY, "La influencia del diálogo 'Hortensio' de Cicerón en San Agustín”, en Anuario Filosófico 34 (2001) 555-564. Asimismo es sugerente el artículo de J.H. TAYLOR, "St. Augustine and the 'Hortensius' of Cicero", en Studies in Philology 60/3 (1963) 487-498.

24 Respecto a la influencia del platonismo cf. CH. BOYER, Christianisme el Néo-platonisme dans la formation de Saint Augustin (Gabriel Beauchesne, Paris 1920), esp. pp. 79-83. 
está lo verdadero, lo que pasa por el cedazo de la interioridad. Esta duda se aplica también a la confianza que, a veces de modo excesivo, damos a las palabras.

Su encuentro con San Ambrosio, quien lo acoge paternalmente, transforma de modo decisivo la idea que San Agustín tiene de la retórica. Si antes la oratoria se le presentaba como un fin en sí mismo, pero que lo llenaba de insatisfacción vital y de inquietud por no aspirar a la verdad sino que básicamente a vencer la posición contraria, en una técnica oratoria que en su tiempo se decantaba muy fuertemente por el género judicial, ahora se convierte en una herramienta interpretativa, hermenéutica, capaz de clarificar aquello que en las Sagradas Escrituras estaba oscuro u oculto, de ir de la letra al espíritu. El Obispo de Hipona ha aprendido que, contra su opinión inicial, no debemos separar tan tajantemente el modo de decir, lo dicho y quien lo dice, pues muchas veces la verdad va internándose en nosotros casi sin que nos demos cuenta, y casi nunca solo por la palabra, sino que también impresionados por quien es capaz de realizar acciones valientes, como de hecho las hizo San Ambrosio, y que claramente influyeron en San Agustín.

Si bien es cierto que ya Aristóteles en su Retórica había considerado el carácter (ethos) como una de las tres pruebas (písteis) retóricas existentes, y en este sentido para el arte mismo no importa la opinión que tengamos de quien realiza el discurso sino lo dicho, en San Agustín este aspecto se potencia decisivamente, y más allá de Cicerón y Quintiliano, al vincular esencialmente la solidez de ese carácter y las palabras dichas con el encuentro de una verdad vivida y no solo aprendida especulativamente y, más aún, todo esto potenciado por la notable maduración de la noción de persona que acompaña de manera permanente la reflexión del Obispo de Hipona.

En definitiva, su preocupación por la retórica no es secundaria en este proceso de encuentro y maduración de la verdad que libera y hace realmente feliz, sobre todo si consideramos los años en los que Agustín fue profesor de este arte —373 en Tagaste, 374 en Cartago, el 383 parte a enseñar a Roma y el 384 es nombrado profesor en Milán_-, si tomamos en cuenta además la buena formación oratoria de San Ambrosio, más 
sólida incluso que la que Agustín obtuviera en su juventud ${ }^{25}$ y, en fin, si reflexionamos en cómo San Agustín escribe una obra con un nombre tan sugerente como De doctrina christiana, dedicada muy centralmente según hemos expuesto a la oratoria eclesiástica, en un período muy amplio de tiempo, pues entre la redacción de esta obra hasta III, 25, 35, y desde ahí hasta concluir el cuarto libro, pasan nada menos que treinta años, desde el 396 al 426 (Retractationes II, 4, 1).

25 P. Brown, La vie de Saint Augustin... 103. 


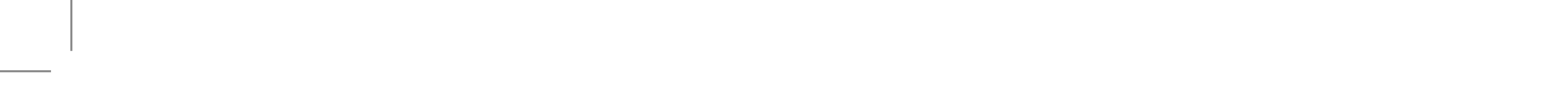




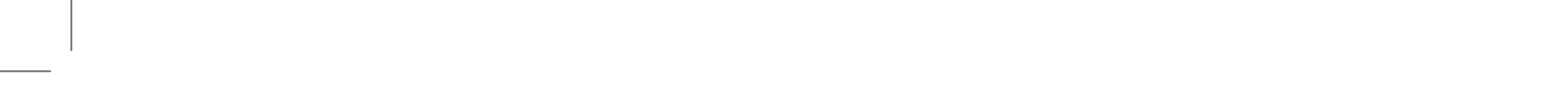

